\title{
A Novel Virus-Like Double-Stranded RNA in an Obligate Biotroph Arbuscular Mycorrhizal Fungus: A Hidden Player in Mycorrhizal Symbiosis
}

\author{
Yoji Ikeda, Hanako Shimura, Ryoko Kitahara, Chikara Masuta, and Tatsuhiro Ezawa
}

Graduate School of Agriculture, Hokkaido University, Sapporo 060-8589 Japan

Submitted 14 November 2011. Accepted 2 March 2012.

\begin{abstract}
Arbuscular mycorrhizal (AM) fungi form mutualistic associations with most land plants and enhance phosphorus uptake of the host plants. Fungal viruses (mycoviruses) that possess a double-stranded RNA (dsRNA) genome often affect plant-fungal interactions via altering phenotypic expression of their host fungi. The present study demonstrates, for the first time, the presence of dsRNAs, which are highly likely to be mycoviruses, in AM fungi. dsRNA was extracted from mycelia of Glomus sp. strain RF1, purified, and subjected to electrophoresis. The fungus was found to harbor various dsRNA segments that differed in size. Among them, a 4.5-kbp segment was termed Glomus sp. strain RF1 virus-like medium dsRNA (GRF1V-M) and characterized in detail. The GRF1V-M genome segment was 4,557 nucleotides in length and encoded RNA-dependent RNA polymerase and a structural protein. GRF1V-M was phylogenetically distinct and could not be assigned to known genera of mycovirus. The GRF1V-M-free culture line of Glomus sp. strain RF1, which was raised by singlespore isolation, produced twofold greater number of spores and promoted plant growth more efficiently than the GRF1V-M-positive lines. These observations suggest that mycoviruses in AM fungi, at least some of them, have evolved under unique selection pressures and are a biologically active component in the symbiosis.
\end{abstract}

Arbuscular mycorrhizal (AM) fungi that belong to the phylum Glomeromycota are ubiquitous in terrestrial ecosystems and form mutualistic associations with most land plants (Smith and Read 2008). The main benefit of the symbiosis for plants is facilitated uptake of immobile nutrients, especially phosphorus $(\mathrm{P})$, through the hyphal networks constructed in the soil; thus, the fungi play a significant role in $\mathrm{P}$ cycling in terrestrial ecosystems. The origin of glomeromycotan fungi is quite ancient: they diverged from other fungi 600 million years ago (Redecker et al. 2000a), and AM associations coincided with the appearance of primitive land plants approximately 400 million years ago (Redecker et al. 2000b; Simon et al. 1993).

Corresponding author: T. Ezawa; Telephone and Fax: +81-11-857-9732; E-mail: tatsu@res.agr.hokudai.ac.jp

The nucleotide sequence data of GRF1V-M and GRF1V-S have been deposited in the DDBJ Data Library under accession nos. AB558119 and AB558120, respectively.

* The $e$-Xtra logo stands for "electronic extra" and indicates that three supplementary figures and two supplementary tables are published online and that Figure 4 appears in color online.
Biological characteristics of the fungi, however, are largely unexplored due to their obligate biotrophic nature.

Fungal viruses (mycoviruses) have been found in a variety of fungi, including the Ascomycetes, Basidiomycetes, and Deuteromycetes (Sasaki et al. 2006). Their genomes are composed of double-stranded RNA (dsRNA) in most cases (Fauquet et al. 2005) and unexceptionally possess an RNA-dependent RNA polymerase (RdRp) gene for replication (Ghabrial and Suzuki 2009). They do not have an extracellular infection route (Buck 1998) but are transmissible vertically via asexual spores (not, or less efficiently, via sexual spores) and horizontally via anastomosis (Hillman et al. 2004). Because no universal artificial infection or elimination system for mycoviruses has been established (Wickner 2001), viral etiologies of altered fungal phenotypes must be understood on each individual species or strain of fungus. Infections of mycoviruses are asymptomatic in many cases but often have a significant impact not only on phenotypic expression of the host fungus (van Diepeningen et al. 2006) but also on higher order biological interactions; for example, attenuation of virulence of a plantpathogenic fungus (Choi and Nuss 1992) and conferring plant thermal tolerance via an endophytic fungus (Márquez et al. 2007). Recently, three mycoviruses - a mitovirus (Stielow et al. 2011b), a totivirus (Stielow and Menzel 2010), and an endornavirus (Stielow et al. 2011a)-have been found in the ectomycorrhizal fungus Tuber aestivum, although their impact on phenotypic expression of the host fungus has yet to be elucidated. These observations led us to hypothesize that AM fungi harbor mycoviruses, which have a major impact on symbiotic interactions; however, thus far, no information about viruses in AM fungi has been reported.

One technical limitation for virological study in AM fungi was the difficulty in obtaining a sufficient amount of pure fungal material for purification of viral particles. Recently, we have established the mesh-bag-separated open-pot culture system for mass production of AM fungal mycelia and applied it to studies on cell fractionation (Tani et al. 2009) and polyphosphate dynamics (Hijikata et al. 2010). It seems unlikely, however, that a sufficient amount of material for virus purification could be obtained even by this system: 30 to $50 \mathrm{~g}$ of tissue are usually used for viral particle purification but more than 70 pots are required to collect approximately $1 \mathrm{~g}$ of mycelia in this system. On the other hand, purity of fungal material is best in the in vitro monoxenic culture (Bécard and Fortin 1988), which has been widely employed for physiological (Bago et al. 2002; Nielsen et al. 2002) and molecular biological (Maldonado-Mendoza et al. 2001) studies, among others, although fungal growth is generally poorer than in open culture. To overcome these problems, we designed the "two-step strategy" in combination with the 
next-generation sequencing technology in the present study: dsRNA viral genomes were first extracted from fungal material produced in the open-pot culture and sequenced "deeply" without purifying a single viral genome; and, subsequently, the presence of the viruses was verified using material produced in the in vitro monoxenic culture by reverse-transcriptase polymerase chain reaction (RT-PCR).

\section{RESULTS}

\section{Detection of dsRNA.}

dsRNA was extracted from 0.4 to $0.9 \mathrm{~g}$ (fresh weight [FW]) of Glomus sp. strain RF1 extraradical mycelia produced in the mesh-bag-separated open-pot culture (Supplementary Fig. S1), treated with DNase I and S1 nuclease that digest DNA and single-stranded (ss)RNA, respectively, and subjected to gel electrophoresis. The fungus was found to harbor several dsRNA segments that differed in size, which were termed Glomus sp. strain RF1 virus-like small dsRNA (GRF1V-S, $2.5 \mathrm{kbp}$ ), medium dsRNA (GRF1V-M, $4.5 \mathrm{kbp}$ ), large dsRNA 1 (GRF1VL1, > $10 \mathrm{kbp}$ ), and large dsRNA 2 (GRF1V-L2, > $10 \mathrm{kbp}$ ) (Fig. 1). Among them, GRF1V-M was chosen for further analysis because the segment was relatively abundant, which was expected to be readily characterized. For this purpose, we employed FLX pyrosequencing, one of the next-generation sequencing technologies, instead of the traditional shotgun library-based sequencing, because at least the three dsRNA segments were coexist with GRF1V-M in the fraction. dsRNAs were reverse-transcribed with the $6 \mathrm{~N}$-anchored primer (Supplementary Table S2), amplified with the anchor primer, and then subjected to pyrosequencing. More than 45,000 reads with an average length of $285 \mathrm{bp}$ were obtained and assembled, and eight large ( $>1 \mathrm{kbp})$ contigs showed amino acid sequence similarities to RdRp and other proteins of four different viruses: 2.5 -kbp contig, Botrytis cinerea debilitationrelated virus in the genus Mitovirus; $4.5-\mathrm{kbp}$ contig, Giardia

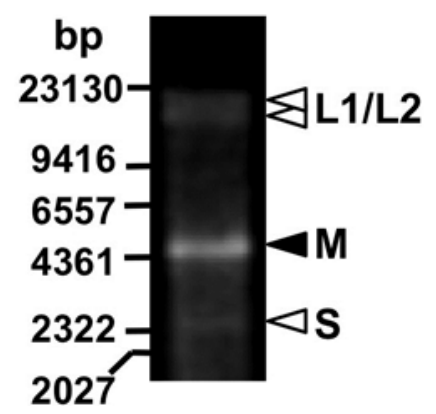

Fig. 1. Double-stranded (ds)RNA segments found in Glomus sp. strain RF1. Total nucleic acid was extracted from mycelia by the sodium dodecyl sulfate-phenol method, treated with DNase I and S1 nuclease, and subjected to electrophoresis on a $0.8 \%$ agarose gel. S, Glomus sp. strain RF1 virus-like small dsRNA (GRF1V-S, $2.5 \mathrm{kbp}$ ); $\mathrm{M}$, medium dsRNA (GRF1V-M, $4.5 \mathrm{kbp}$ ); and L1/L2, large dsRNA 1 and dsRNA 2 (GRF1VL1 and GRF1V-L2, >10 kbp). GRF1V-M was characterized in detail. canis virus in the genus Giardiavirus; 2.6-, 3.7-, and 5.9-kbp contigs, Phytophthora endornavirus 1 in the genus Endornavius; and 1.0-, 1.3-, and 4.2-kbp contigs, Phlebiopsis gigantea mycovirus dsRNA 1 that was an unclassified totivirus (Supplementary Table S1). To examine the identity between these contigs and the dsRNA segments detected in the gel, GRF1V-S, GRF1V-M, and GRF1V-L1 and -L2 were re-extracted from the gel separately. GRF1V-L1 and -L2 were collected together (L1/L2) because the two could not be clearly separated on the gel. Nested PCR assays were then conducted by using these dsRNAs and the primers specific to each contig after reversetranscription with the $6 \mathrm{~N}$ primer. As expected, the amplified fragments had sequences identical to the 2.5 -kbp mitoviruslike contig, 4.5-kbp giardiavirus-like contig, 5.9-kbp endornavius-like contig, and 4.2-kbp totivirus-like contigs, which were obtained from the fractions of GRF1V-S, GRF1V-M, GRF1VL1/L2, and GRF1V-L1/L2, respectively (Supplementary Fig. $\mathrm{S} 2$ ). Thus, these results confirmed the direct linkage between the contigs and the dsRNAs. Then, the presence of the viruslike dsRNAs in the in vitro monoxenic culture was further examined by RT-PCR tests using the dsRNA fraction prepared from the in vitro-produced spores as template. Target PCR fragments were successfully obtained with the primer sets specific to GRF1V-S and -M (Supplementary Fig. S3) but not with those specific to GRF1V-L1 and -L2, indicating that at least GRF1V-S and -M were of AM fungal origin.

\section{Molecular characterization of GRF1V-M.}

To obtain full-length sequences of GRF1V-M, approximately $100 \mathrm{bp}$ of each of the $5^{\prime}$ - and $3^{\prime}$-terminal sequences were determined or confirmed by rapid amplification of cDNA ends. The segment is 4,557 nucleotides (nt) in length and consists of a $5^{\prime}$ untranslated region (UTR) of $40 \mathrm{nt}$, two open reading frames (ORF) (ORF 1 and ORF 2) encoding polypeptides of 927 and 537 amino acids, respectively, and a 3' UTR of 102 nt that includes a 19-nt poly(A) tail in the plus-sense strand (Fig. 2). No notable ORF was found in the minus-sense strand. A preliminary BLAST search revealed that the protein encoded by ORF 1 had similarities to RdRps of the members of the family Totiviridae but, surprisingly, the highest score was observed with RdRps of protozoan viruses, followed by those of the viruses found in salmon, fruit fly, mosquito, and shrimp, which were included in subsequent phylogenetic analysis. The ORF 1 protein conserved a domain of the viral RdRp superfamily (Pfam accession number PF02123) and its motifs I to VIII, including the SG---TS/T and GDD motifs (Chiba et al. 2009; Ghabrial 1998) (Fig. 3A). The protein encoded by ORF 2 showed similarity to the $\mathrm{S} 7$ viral core protein of the Rice dwarf virus (Phytoreovirus) that is suggested to have binding activity to the genomic RNA, RdRp, and other viral structural proteins (Hagiwara et al. 2003; Ueda et al. 1997). The domain of the Phytoreovirus S7 protein superfamily (Pfam accession number PF07236) was also conserved in the ORF 2 protein (Fig. 3B). Therefore, we considered that ORF 2 might encode a structural protein that binds to and protects the genomic RNA.

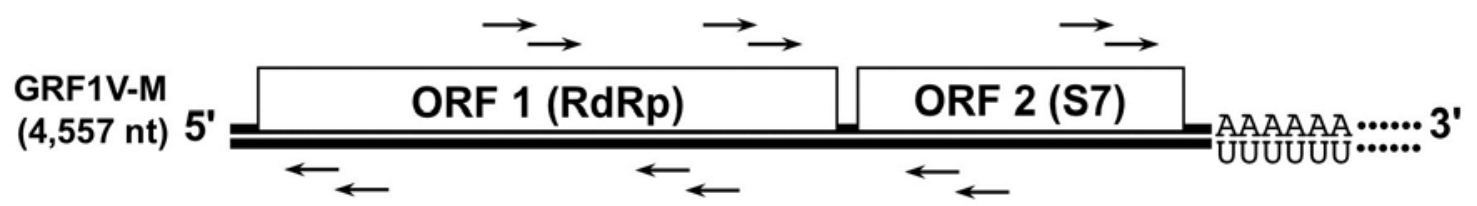

Fig. 2. Genome organization of Glomus sp. strain RF1 virus-like medium double-stranded RNA (GRF1V-M). The segment is 4,557 nucleotides (nt) in length and possesses open reading frame (ORF) 1 (927 codons) and ORF 2 (537 codons) that are predicted to encode RNA-dependent RNA polymerase (RdRp) and a S7 structural protein (S7), respectively. A 19-nt poly(A)-tail is present at the $3^{\prime}$ untranslated region. Relative positions of primers used for $5^{\prime}$ or $3^{\prime}$ rapid amplification of cDNA ends, for detection from the in vitro culture (in the middle of ORF 1), and for confirmation of the genome organization (between the $3^{\prime}$ end of ORF 1 and $5^{\prime}$ end of ORF 2) are indicated. 
Because the genome organization of GRF1V-M, in which an RdRp gene was encoded by the $5^{\prime}$-proximal ORF, was unique and had not been described within the members of Totiviridae, the region between the $3^{\prime}$ end of ORF 1 and $5^{\prime}$ end of ORF 2 was amplified by nested PCR with the specific primers (Fig. 2 ), cloned, and sequenced, which resulted in confirmation of the sequence obtained by pyrosequencing.

\section{Phylogeny of GRF1V-M.}

To clarify the evolutionary position of GRF1V-M, phylogenetic analyses were conducted based on the amino acid sequence of RdRp genes, the most highly conserved gene among RNA viruses (Ghabrial 1998). A phylogenetic tree was constructed first with the representative members from all genera of dsRNA mycoviruses. As expected from the preliminary BLAST search, GRF1V-M formed no robust cluster with any of them (Fig. 4A). Therefore, subsequent analysis was conducted with the members of Totiviridae, which includes not only mycoviruses but also protozoan and animal viruses. Again, GRF1V-M formed no robust cluster but, as predicted by the preliminary search, was more closely related to the protozoan (Giardiavirus) and animal viruses than the mycoviruses (Fig. 4B).

\section{Impact of GRF1V-M infection on Glomus sp. strain RF1 phenotype.}

To assess the impact of GRF1V-M on phenotypic expression of the host fungus by comparing GRF1V-M-free and -positive fungal cultures, single-spore culture lines (open culture) were raised, which has often been employed in other fungi to obtain virus-free culture (Hillman et al. 2004) and also in an AM fungus to cure endosymbiotic bacteria (Lumini et al. 2007). Twelve culture lines were successfully established (first generation), and the presence or absence of GRF1V-S, -M, -L1, and -L2 in each line was examined by RT-PCR on the dsRNA fractions prepared from the spores. GRF1V-S, -L1, and L2 were present in all lines but, fortunately, one of the lines (line 3) was found to be GRF1V-M free. The second generation of the lines was raised from 100 to 200 spores produced in the first generation to obtain enough spores for subsequent inoculation experiments, and the presence or absence of the dsRNAs in the generation was further confirmed by RT-PCR.

Spore productivity, which could be assessed only during symbiosis with plants, was employed as an index of fungal re- productive or competitive potential. Sorghum, one of the greatest spore producers (Smith and Read 2008), was inoculated with either the GRF1V-M-free or -positive line and grown on sand culture in a greenhouse, and spores were harvested 20 weeks after sowing, at which time maximum spore production was expected. The GRF1V-M-free line produced at a density of more than 130 spores per gram of sand but the GRF1V-Mpositive lines produced only 37 to $63 \%$ (50 to 85 spores per gram of sand) of that of the free line (Fig. 5).

The impact of GRF1V-M on plant symbiotic growth was assessed under both acidic ( $\mathrm{pH} 3.4)$ and nonacidic $(\mathrm{pH} 5.7)$ conditions, because Glomus sp. strain RF1 was originally isolated from acidic soil and was highly acid tolerant (unpublished observation). As a host plant, Miscanthus sinensis, a $\mathrm{C}_{4}$ perennial grass species, was chosen. Although this species grows more slowly and produces fewer spores than sorghum, it is highly acid tolerant (Kayama 2001; Maki et al. 2008) and, thus, more suitable for the assessment than sorghum, the growth of which is largely limited by soil acidity (Caniato et al. 2007). M. sinensis was inoculated with either the GRF1VM-free or -positive line and grown in the greenhouse for 8 weeks, by which time plant growth was not limited by the pot size (though sporulation was minimum). Both the free and positive lines promoted plant growth to the same extent at $\mathrm{pH}$ 5.7, compared with the nonmycorrhizal control (Fig. 6). At pH 3.4 , shoot growth was greater in those inoculated with the free line than with the positive line, although no significant difference in root growth was observed between the two lines. The level of mycorrhizal colonization was not different between the free and positive lines at both $\mathrm{pH} 5.7$ and 3.4.

\section{DISCUSSION}

The present study demonstrates, for the first time, that the obligate plant symbionts AM fungi harbored diverse dsRNAs, which are highly likely to be mycoviruses. The two-step strategy, in which molecular characterization was conducted using material from the open culture and the presence was verified by RT-PCR using a small amount of material produced in vitro, was indispensable for the successful detection and characterization of dsRNA in AM fungi, in addition to next-generation sequencing. Traditionally, molecular characterization of a new virus starts from purification of viral particles, fol-

\section{A Viral RdRp motifs}

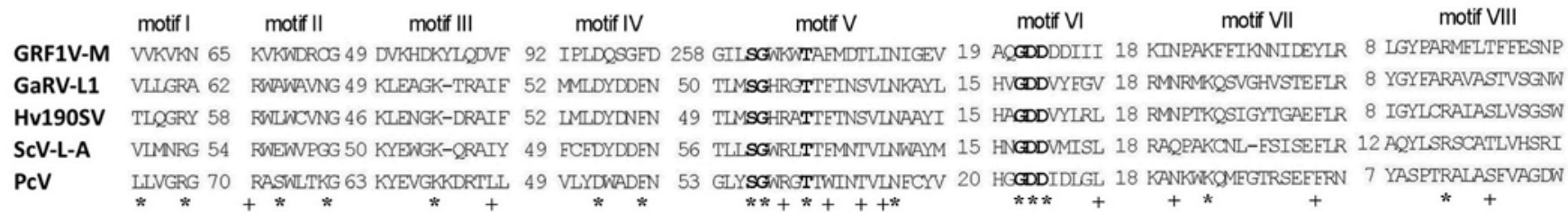

\section{B Phytoreovirus S7 protein motifs}

\begin{tabular}{|c|c|c|c|c|c|}
\hline & motif I & motif II & motif III & motif IV & motif $\mathrm{V}$ \\
\hline GR & NILRRKWLWNDTLSRKVLICHSPDQL & PSGVRVLCILNSNSLNVNK & 3 SLQNRHSL & WENYRD & 2 NYFEVQSNKVMLDTII \\
\hline RdV & SETISKHVSDGSYGNRVIISHKMSRL & NGGVKIIGRFKISDENTVK & 12 SRSGEIDS 4 & WEALSG & NGLVTDSNISMLHDKI \\
\hline WTV & $\begin{array}{c}\text { NQLVRKYLRQGYYGNKVILGHHPDNL } \\
*++* * * *\end{array}$ & PNGISIIGVYALDSESNLE & $\begin{array}{l}7 \text { SLKNRLDL } 4 \\
*\end{array}$ & WKEIRD & $\begin{array}{r}\text { KITVVAPTIQELHHII } \\
* * *\end{array}$ \\
\hline
\end{tabular}

Fig. 3. Protein motifs found in the predicted open reading frames (ORFs) in Glomus sp. strain RF1 virus-like medium double-stranded RNA (GRF1V-M). A, Alignment of viral RNA-dependent RNA polymerase motifs I to VIII (Pfam accession number PF02123) encoded by GRF1V-M and the members of genera Victorivirus (GaRV-L1 and Hv190SV), Totivirus (ScV-L-A), and Chrysovirus (PcV). The SG---TS/T and GDD motifs are highlighted by bold letters. B, Alignment of Phytoreovirus S7 protein motifs I to V (Pfam accession number PF07236) encoded by GRF1V-M and the members in genus Phytoreovirus (RdV and WTV). Abbreviated viral names and accession numbers: GaRV-L1, Gremmeniella abetina RNA virus L1 (AAK11656); Hv190SV, Helminthosporium victoriae virus 190 S (AAB94791); PcV, Penicillium chrysogenum virus (YP_392482); ScV-L-A, Saccharomyces cerevisiae virus L-A (NP_620495); RdV, Rice dwarf virus (NP_620543); WTV, Wound tumor virus (P12325). 
lowed by random amplification of cDNA fragments from the viral genome and sequencing of the shotgun library. Recently, FLX pyrosequencing has been applied to the detection or genome sequencing of new viral pathogens in medical (Feng et al. 2008; Nakamura et al. 2009; Spatz and Rue 2008) and entomological (Cox-Foster et al. 2007) sciences but, thus far, this is the first application for fungal virology. The combination of open and in vitro cultures with the next-generation sequencing could be a breakthrough for discovery and molecular characterization of new viruses in unculturable fungi, from which a sufficient amount of material for purification of viral particles is difficult to obtain.

We consider that GRF1V-M is highly likely to be an RNA mycovirus for the following two reasons: i) ORF 1 was predicted to encode the replicase RdRp, which may be responsible for genome replication, and ii) the GRF1V-M segment disappeared in one of the single-spore culture lines but remained in the other lines, in which the segment was inherited in the next generation. These observations strongly suggest that GRF1V-M is "self-replicative" and "transmissible from generation to generation" and, thus, meets the prerequisite features of (myco)viruses.

Although the GRF1V-M segment was found in the dsRNA fraction, it has not yet been confirmed whether GRF1V-M possesses a dsRNA genome or an ssRNA genome, because a replicative form of ssRNA viruses could also coexist in a dsRNA fraction. We consider, however, that our observations are in favor of dsRNA. For example, the RdRp gene was most closely related to dsRNA viruses, and both the RdRp and S7 core protein motifs of dsRNA viruses were conserved. In a preliminary experiment, cDNA of the viral genome could be synthesized and amplified from total RNA with the $3^{\prime}$ end oligo(dT) primer in combination with the $5^{\prime}$-end primers using the boiled (denatured) RNA preparation but not without boiling, suggesting that no (or minimum) ssRNA form of GRF1V-M was present in the preparation. Purification of the viral particles, however, may be necessary to exclude the possibility that GRF1V-M is an ssRNA virus, if the particles really exist. We assume that the genome may be encapsulated by the S7 core protein (encoded by ORF 2) or, more likely, only associated with the protein to protect the virus from nucleases, because the $\mathrm{S} 7$ core protein may not be a real capsid protein (Hagiwara et al. 2003; Ueda et al. 1997). To understand the structure, the first step we are planning is immunoprecipitation of GRF1V-M using antibodies raised against the $\mathrm{S} 7$ core protein.

GRF1V-M is evolutionarily distinct. Although the phylogenetic analysis indicated that the RdRp gene of GRF1V-M is related to Totiviridae, GRF1V-M cannot be assigned to Totiviridae due to the unique genome structure: an RdRp gene is encoded by the $5^{\prime}$-proximal ORF in GRF1V-M but by the $3^{\prime}$ proximal ORF in Totiviridae, and a $3^{\prime}$-poly(A) tail is present in GRF1V-M but absent in Totiviridae (Fauquet et al. 2005). On the other hand, the protein encoded by ORF 2 conserves the
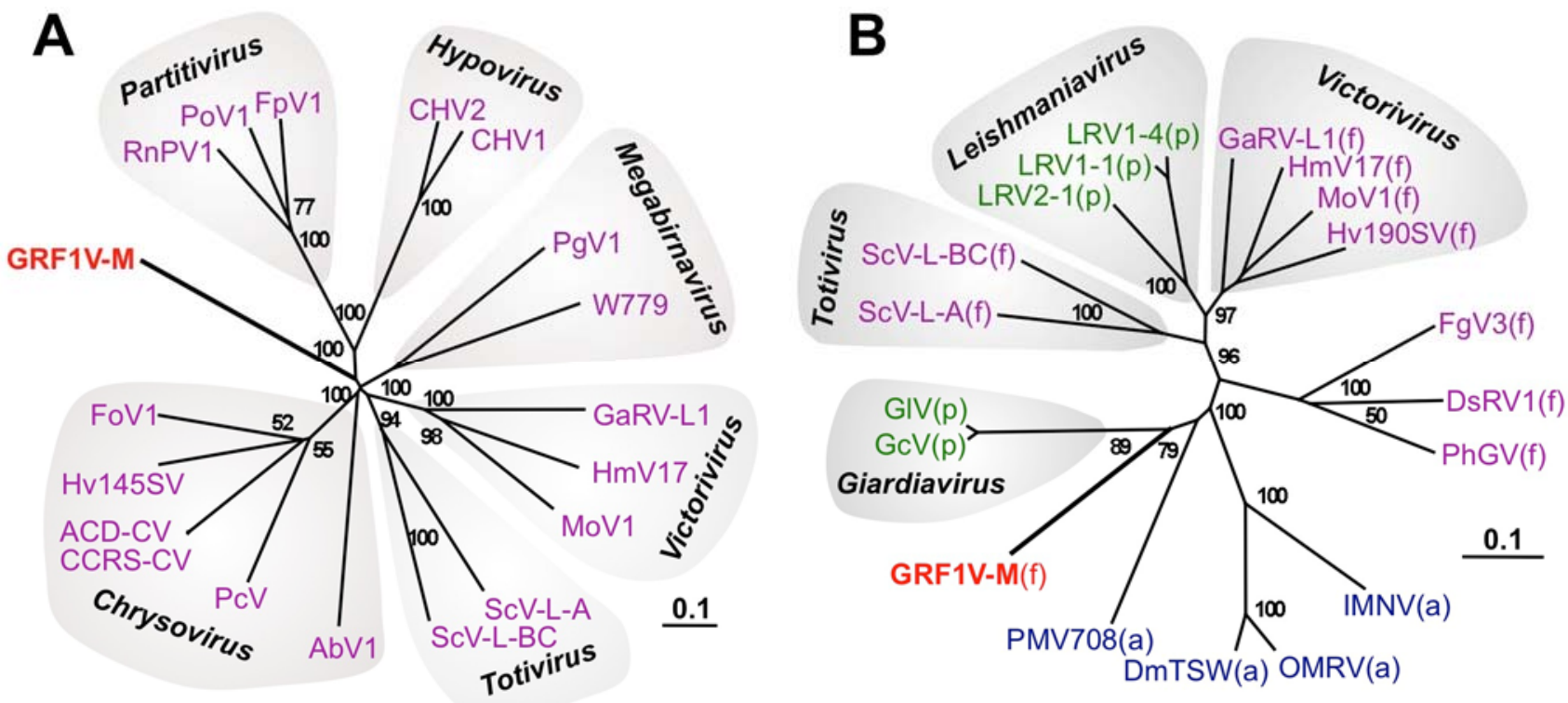

Fig. 4. Phylogenetic analysis of Glomus sp. strain RF1 virus-like medium double-stranded RNA (GRF1V-M) based on the amino acid sequences of RNAdependent RNA polymerase. A, Analysis with all genera of double-stranded (ds)RNA mycoviruses. Note that PgV1 has not been confirmed to be a member of genus Megabirnavirus. B, Analysis with the animal (a), protozoan (p), and fungal (f) viruses in the family Totiviridae and with the unclassified dsRNA fungal viruses (FgV3, DsRV1, and PhGV) to which GRF1V-M RNA-dependent RNA polymerase showed similarities. Multiple sequence alignments were implemented by Clustal X and modified manually, and the neighbor-joining trees were drawn by NJplot. The tree topologies were confirmed by comparing with the maximumlikelihood trees constructed by the $\mathrm{LG}+\mathrm{I}+\mathrm{G}$ model following the Akaike information criterion. Numbers at the nodes represent bootstrap values (\%) for 1,000 trials. Scale bars represent 0.1-amino-acid substitutions per site corresponding to branch length. Abbreviated virus names and accession numbers: AbV1, Agaricus bisporus virus 1 (CAA64144); ACD-CV, Amasya cherry disease-associated chrysovirus (YP_001531163); CCRS-CV, Cherry chlorotic rusty spot-associated chrysovirus (CAH03664); CHV1, Cryphonectria hypovirus 1-EP713 (Q04350); CHV2, Cryphonectria hypovirus 2-NB58 (AAA20137); DmTSW, Drosophila melanogaster totivirus SW-2009a (YP_003289293); DsRV1, Diplodia scrobiculata RNA virus 1 (YP_003359178); FgV3, Fusarium graminearum dsRNA mycovirus-3 (YP_003288789); FoV1, Fusarium oxysporum chrysovirus 1 (ABQ53134); FpV1, Fusarium poae virus 1 (AF047013); GaRV-L1, Gremmeniella abetina RNA virus L1 (AAK11656); GcV, Giardia canis virus (ABB36743); GlV, Giardia lamblia virus (AAB01579); HmV17, Helicobasidium mompa Number17 dsRNA virus (NP_898833); Hv145SV, Helminthosporium victoriae 145S virus (YP_052858); Hv190SV, Helminthosporium victoriae virus 190S (AAB94791); IMNV, Penaeid shrimp infectious myonecrosis virus (YP_529549); LRV1-1, Leishmania RNA virus 1-1 (NP_041191); LRV1-4, Leishmania RNA virus 1-4 (NP_619653); LRV2-1, Leishmania RNA virus 2-1 (NP_043465); MoV1, Magnaporthe oryzae virus 1 (NP_624349); OMRV, Omono River virus (BAJ21511); PcV, Penicillium chrysogenum virus (YP_392482); PhGV, Phlebiopsis gigantea mycovirus dsRNA 2 (CAJ34335); PgV1, Phlebiopsis gigantea mycovirus dsRNA1 (CAJ34333); PMV708, Piscine myocarditis virus AL V-708 (ADP37187); PoV1, Pleurotus ostreatus virus 1 (ACX43951); RnPV1, Rosellinia necatrix partitivirus 1-W8 (NC_007537); ScV-L-A, Saccharomyces cerevisiae virus L-A (NP_620495); ScV-L-BC, Saccharomyces cerevisiae virus L-BC (NP_042581); W779, Rosellinia necatrix megabirnavirus 1/W779(YP_003288763). 
domain of a structural protein of the plant dsRNA virus Phytoreovirus. These results, in addition to the fact that glomeromycotan fungi are ancient and have a long history of coevolution with land plants, support the idea that GRF1V-M might have been generated through extensive recombination events among ancestors of the protozoan, animal, and plant viruses, which occurred during the era of eukaryogenesis (Koonin et al. 2008).

Extensive phenotypic variations have been observed not only among AM fungal species but also within the individual species, and this has generally been considered to be due to the genetic diversity of AM fungi as a consequence of the multigenomic nature (Koch et al. 2004). The intracellular symbiotic bacterium 'Candidatus Glomeribacter gigasporarum' in the AM fungus Gigaspora margarita has been shown to be a nongenetic but heritable (transmissible) component that altered phenotypic expression of the host fungus (Lumini et al. 2007; Salvioli et al. 2010). The alteration of phenotype by the bacterium, however, was observed only in the presymbiotic stages, not in the symbiotic stages. The present study demonstrates that the GRF1V-M altered the symbiotic phenotypes (i.e., spore productivity and the plant-growth-promoting effect) of the host fungus Glomus sp. strain RF1, providing a new possible interpretation for the extensive phenotypic variability in AM fungi: mycoviruses would be a biologically active-transmissible component and definitely a potential player responsible for the phenotypic variability.

Although the molecular mechanism underlying the phenotypic alteration by GRF1V-M is obscure, ecological relevance of the reduced spore productivity and plant-growth-promoting effect of Glomus sp. strain RF1 is of interest. It has been suggested that considerable photosynthetic carbon is allocated to the fungal symbiont for sporulation (Smith and Read 2008). Therefore, the reduction in spore productivity in Glomus sp. strain RF1 likely leads to the idea that GRF1V-M improves overall carbon economy of the association via saving excess

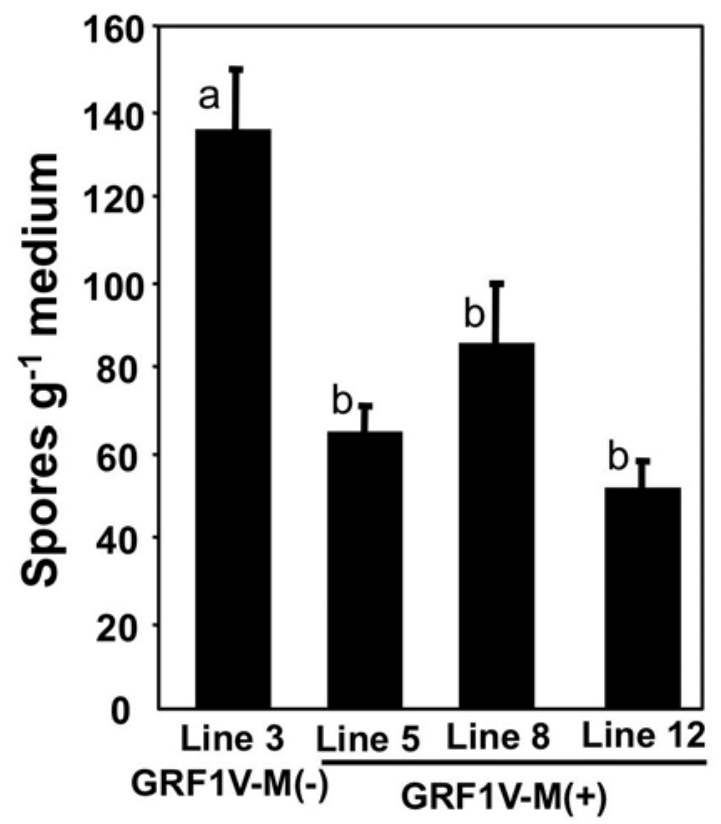

Fig. 5. Spore productivity of the Glomus sp. strain RF1 virus-like medium double-stranded RNA (GRF1V-M)-free and -positive culture lines of Glomus sp. strain RF1. The free (line 3) and positive (lines 5, 8, and 12) culture lines were grown in the sand culture with sorghum in a greenhouse for 20 weeks, and spores formed in the medium were extracted by the wet sieving and counted under a stereomicroscope. Different letters indicate significant difference $(P<0.05$, Tukey-Kramer test). Vertical bars indicate standard error $(n=3)$. consumption of carbon. On the other hand, we consider that the impact on plant growth may be limited, because the GRF1V-M-positive line could still improve plant growth compared with the nonmycorrhizal plants under acidic conditions and the percentage of mycorrhizal colonization, which may reflect infectivity of the fungus, was not significantly different between the GRF1V-M-positive and -free lines. Given that soil acidity is the major selection pressure on AM fungi (An et al. 2008), it is likely that the acidic stress ( $\mathrm{pH} \mathrm{3.4)} \mathrm{in} \mathrm{the} \mathrm{experi-}$ mental conditions was so severe for the fungus that a negative impact of GRF1V-M (e.g., a decline in fungal fitness via exploitation of cellular resource due to GRF1V-M proliferation) might be enhanced. Accordingly, further investigation is necessary to elucidate direct relevance of the reduced spore productivity to plant competitiveness with respect to soil acidity.

We could detect the large dsRNAs GRF1V-L1 and -L2 in the open-culture spores but the presence of the large segments in the in vitro culture has not yet been confirmed. Although relative abundance of the dsRNAs in the fungus has not been estimated, it seems that GRF1V-L1 and -L2 are much less abundant than GRF1V-M (Fig. 1), which may be one reason why they could not be amplified from a small amount of material. An attempt to increase the yield and purity of dsRNA from a small amount of material is being undertaken for successful detection of GRF1V-L1 and -L2 in the in vitro culture.

In conclusion, the present study sheds new light on AM symbiosis from the viewpoint of virology. The demonstration of the technical feasibility of dsRNA manipulation, at least elimination, implies that improvement or innovation of the symbiotic performance of AM fungi would be possible with-

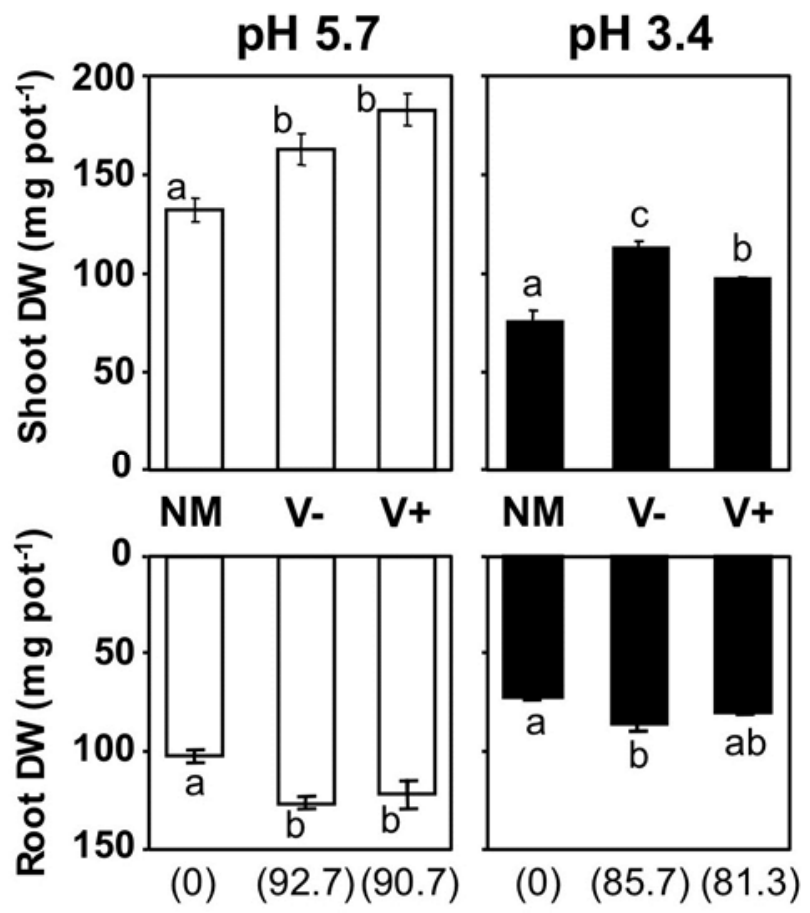

Fig. 6. Plant-growth-promoting effect of the Glomus sp. strain RF1 viruslike medium double-stranded RNA (GRF1V-M)-free and -positive culture lines of Glomus sp. strain RF1 with respect to soil $\mathrm{pH}$. The pioneer grass species Miscanthus sinensis was inoculated with either the free (V-, line 3) or positive $(\mathrm{V}+$, line 8$)$ culture line and grown on acidic $(\mathrm{pH} 3.4)$ or nonacidic ( $\mathrm{pH}$ 5.7) soil for 8 weeks. Nonmycorrhizal plants (NM) were grown as controls. Different letters indicate significant difference $(P<0.05$, Tukey-Kramer test). Vertical bars indicate the standard error $(n=5)$. Numbers in parentheses are the levels of mycorrhizal colonization (\%) at 8 weeks. No significant difference in the levels of colonization was observed between the free and positive lines at $P<0.05$. 
out genetic manipulation of the fungi. It is expected that the presence, absence, or molecular feature of mycoviruses would be applicable as a biological marker for identification of geographical isolates and anastomosis groups, because spore formation and anastomosis are the only likely routes of mycovirus transmission. The fact that a novel viral dsRNA was discovered in our very first and limited survey suggests that viruses in AM fungi, at least some of them, may have evolved under unique selection pressures and that further discovery of new viral dsRNA from AM fungi seems highly probable, which will contribute to understanding the coevolution between viruses and glomeromycotan fungi.

\section{MATERIALS AND METHODS}

\section{Fungal isolates.}

Glomus sp. strain RF1 (MAFF520086) was isolated from the rhizosphere of Petasites japonicus var. giganteus grown in acid sulfate soil $(\mathrm{pH}<4)$ in Japan, and the small subunit rRNA gene sequences (GenBank accession number AB220173) showed similarity to those of $G$. manihotis and G. clarum in Glomus group A. The stock culture of the isolate was established from multiple spores (approximately 50 spores) and has been maintained in sand culture in a temperature- and lightcontrolled (26 and $20^{\circ} \mathrm{C}$, day and night, respectively, with14-h day length) greenhouse using sorghum and groundnut as host plants.

\section{Open and in vitro culture systems.}

To obtain fungal material for dsRNA extraction and characterization, the mesh-bag-separated open-pot culture system was employed (Tani et al. 2009). Lotus japonicus L. 'Miyakojima MG-20' (National Bioresource Project Legume Base) was pregerminated on moistened filter paper at $25^{\circ} \mathrm{C}$ in the dark for $24 \mathrm{~h}$. Three seedlings were transplanted to the mycorrhizal compartment (MC) (26 ml in volume) of the mesh-bag culture system in a $120-\mathrm{ml}$ plastic pot $(6 \mathrm{~cm}$ in diameter $)$ and inoculated with the fungus at 1,000 spores per pot. The mesh-bag system consisted of the MC and hyphal compartment (HC) that were separated by a cone-shaped $37-\mu \mathrm{m}$ nylon mesh bag, and both compartments were filled with autoclaved river sand. The pore size of the nylon mesh was small enough to prevent L. japonicus roots from passing but large enough to allow AM fungal hyphae to pass through. The plants were grown in a growth chamber at a photosynthetic photon flux of $150 \mu \mathrm{mol}$ $\mathrm{m}^{-2} \mathrm{~s}^{-1}$ (16-h day length, $25^{\circ} \mathrm{C}$ ) for a week only with deionized water, thinned to two plants pot $^{-1}$, and further grown with low-P nutrient solution $\left(4 \mathrm{mM} \mathrm{NH} \mathrm{NO}_{3}, 1 \mathrm{mM} \mathrm{K} \mathrm{SO}_{4}, 75 \mu \mathrm{M}\right.$ $\mathrm{MgSO}_{4}, 2 \mathrm{mM} \mathrm{CaCl}{ }_{2}, 50 \mu \mathrm{M}$ Fe-EDTA, and $50 \mu \mathrm{M} \mathrm{KH}_{2} \mathrm{PO}_{4}$ ) for 7 weeks. After removing the MC, extraradical mycelium in the $\mathrm{HC}$ was harvested from 72 pots by wet sieving, blotted on a filter paper, weighed, frozen in liquid nitrogen, and stored at $-80^{\circ} \mathrm{C}$ for dsRNA extraction. In this process, 0.4 to $0.9 \mathrm{~g} \mathrm{FW}$ of mycelia could normally be collected.

To obtain single-spore culture lines of Glomus sp. strain RF1, L. japonicus seedlings were pregerminated, transplanted to the 6-cm plastic pot filled with autoclaved river sand without the mesh bag, inoculated with a single spore produced in the stock culture, and grown in the growth chamber for 2 months under the same conditions as those for the mesh-bag culture system (first generation). For further proliferation, sorghum was inoculated with 100 to 200 spores produced in the first generation and grown in the sand culture in the greenhouse for 4 months (second generation).

The in vitro monoxenic culture of Glomus sp. strain RF1 was raised from five spores produced in the stock culture using the $\mathrm{Ri}$ T-DNA-transformed carrot roots (Bécard and Fortin
1988) and maintained at $27^{\circ} \mathrm{C}$ in the dark. For dsRNA detection, spores were collected after melting the medium by shaking in $0.5 \mathrm{M}$ EDTA solution.

\section{dsRNA extraction, sequencing, and virus detection.}

dsRNA was extracted from the frozen mycelia ( 0.4 to $0.9 \mathrm{~g}$ ) by the sodium dodecyl sulfate-phenol method (Suzuki et al. 2003), purified by incubating with DNase I at 0.4 units $\mu 1^{-1}$ and $\mathrm{S} 1$ nuclease at 3.4 units $\mu \mathrm{l}^{-1}$ (Takara Bio, Tokyo) at $37^{\circ} \mathrm{C}$ overnight according to Osaki and associates (2002), and electrophoresed on a $0.8 \%$ agarose gel. For sequencing, dsRNA segments were eluted from the gel pieces in the GeBAflex dialysis tube (25-kDa cut-off; Gene Bio-Application, Kfar Hanagide, Israel), purified again by overnight incubation with DNase I and S1 nuclease, reverse-transcribed using the $6 \mathrm{~N}$ anchored primer, and amplified using the anchor primer with Taq polymerase. The program of the thermal cycler was as follows: initial denaturation at $94^{\circ} \mathrm{C}$ for $2 \mathrm{~min}$; followed by 40 cycles at $94^{\circ} \mathrm{C}$ for $15 \mathrm{~s}, 55^{\circ} \mathrm{C}$ for $30 \mathrm{~s}$, and $72^{\circ} \mathrm{C}$ for $2 \mathrm{~min}$; with a final extension at $72^{\circ} \mathrm{C}$ for $10 \mathrm{~min}$. The PCR product was sequenced using the Genome Sequencer FLX system with a one-eighth-scale gasket (Roche Diagnostics, Tokyo) and assembled using the SeqNova Data Analysis System at Hokkaido System Science Co., Ltd. (Sapporo, Japan). The sequences of the extreme ends of the dsRNA segment were amplified using the specific primers, cloned, and sequenced by the dideoxycycle sequencing method.

For specific detection of each dsRNA segment in the open culture material, dsRNA prepared from the electrophoretic gel pieces or from 500 to 1,000 spores was used as RT-PCR template; whereas, for the detection from the in vitro culture, the template dsRNA was prepared from 200 to 300 spores. dsRNA was reverse-transcribed with the $6 \mathrm{~N}$-random primer, amplified by nested PCR using the specific primers with the following thermal cycle program: initial denaturation at $94^{\circ} \mathrm{C}$ for $2 \mathrm{~min}$; followed by 40 cycles at $94^{\circ} \mathrm{C}$ for $15 \mathrm{~s}, 62^{\circ} \mathrm{C}$ for $30 \mathrm{~s}$, and $72^{\circ} \mathrm{C}$ for $45 \mathrm{~s}$; with a final extension at $72^{\circ} \mathrm{C}$ for $10 \mathrm{~min}$. The PCR products were subjected to gel electrophoresis, cloned, and sequenced for confirmation.

\section{Sequence analysis and phylogeny.}

The contigs obtained by pyrosequencing were subjected to BLAST searches. ORF and motif searches were performed with the Vector NTI (Invitrogen, Tokyo) and the Position-Specific Iterated BLAST against the Pfam database, respectively. Multiple sequence alignments were implemented by Clustal X (Thompson et al. 1997), which was carefully edited or modified by eye as described previously (Chiba et al. 2009). Neighbor-joining trees were constructed based on the alignments of RdRp sequences and displayed by TreeView. For analysis with the representative mycovirus members, an alignment of the RdRp sequences from motifs III to VIII was employed due to the absence of motifs I and II in the members of the families Partitiviridae and Hypoviridae, and an alignment of the sequences from motifs I to VIII was employed for analysis with the members of Totiviridae. Tree topologies were confirmed by comparing with maximum-likelihood trees constructed using the best-fit model selected by the ProtTest 2.4 following the Akaike information criterion (Abascal et al. 2005). The GenBank accession numbers of viral sequences used in the motif and phylogenetic analyses were listed in Supplementary Table S3.

\section{Impact of GRF1V-M infection on fungal phenotype.}

To examine spore productivity, sorghum was inoculated with 100 spores of either the GRF1V-M-free or -positive culture lines of Glomus sp. strain RF1 and grown in 9-cm plastic 
pots $(350 \mathrm{ml}$ in volume) filled with river sand in the greenhouse for 20 weeks, during which the low-P nutrient solution was applied every other day ( 2 plants $\left.\operatorname{pot}^{-1}, n=3\right)$. Spores produced in the pots were collected by wet sieving and counted under a stereomicroscope. For assessment of the plant-growthpromoting effect of the GRF1V-M-free and -positive culture lines, acid sulfate soil ( $\mathrm{pH}$ 3.4) collected from Rankoshi, Hokkaido, Japan (An et al. 2008) was autoclaved and divided into two parts: one part was mixed with calcium carbonate at $12 \mathrm{~g}$ $\mathrm{kg}^{-1}$ to adjust the $\mathrm{pH}$ to 5.7 and the other was not. $M$. sinensis was sown on either of the soils in $9 \mathrm{~cm}$ plastic pots, inoculated with 1,000 spores of the free or positive culture line, and grown in the greenhouse for 8 weeks, during which the plants received only tap water (10 plants pot $\left.^{-1}, n=5\right)$. After harvest, shoot and root dry weights were measured, and percentages of mycorrhizal colonization were assessed by the gridline intersection method (Giovannetti and Mosse 1980).

\section{ACKNOWLEDGMENTS}

This study was supported by the Grant-in-Aid for Scientific Research (22380042) from Japan Society for the Promotion of Science (T. Ezawa) and the Asahi Glass Foundation (C. Masuta and T. Ezawa). M. sinensis seed was kindly provided by N. Fukuda (Kaiseisha Co., Hokkaido, Japan). We also thank anonymous reviewers for their kind suggestions and comments that strongly encouraged us and improved the quality of the study.

\section{LITERATURE CITED}

Abascal, F., Zardoya, R., and Posada, D. 2005. ProtTest: selection of bestfit models of protein evolution. Bioinformatics 21:2104-2105.

An, G.-H., Miyakawa, S., Kawahara, A., Osaki, M., and Ezawa, T. 2008. Community structure of arbuscular mycorrhizal fungi associated with pioneer grass species Miscanthus sinensis in acid sulfate soils: Habitat segregation along $\mathrm{pH}$ gradients. Soil Sci. Plant Nutr. 54:517-528.

Bago, B., Zipfel, W., Williams, R. M., Jun, J., Arreola, R., Lammers, P. J., Pfeffer, P. E., and Shachar-Hill, Y. 2002. Translocation and utilization of fungal storage lipid in the arbuscular mycorrhizal symbiosis. Plant Physiol. 128:108-124.

Bécard, G., and Fortin, J. A. 1988. Early events of vesicular-arbuscular mycorrhiza formation on Ri T-DNA transformed roots. New Phytol. 108:211-218.

Buck, K. W. 1998. Molecular variability of viruses of fungi. Pages 53-72 in: Molecular Variability of Fungal Pathogens. CAB International, Dordrecht, The Netherlands.

Caniato, F., Guimarães, C., Schaffert, R., Alves, V., Kochian, L., Borém, A., Klein, P., and Magalhaes, J. 2007. Genetic diversity for aluminum tolerance in sorghum. Theor. Appl. Genet. 114:863-876.

Chiba, S., Salaipeth, L., Lin, Y.-H., Sasaki, A., Kanematsu, S., and Suzuki, N. 2009. A novel bipartite double-stranded RNA mycovirus from the white root rot fungus Rosellinia necatrix: Molecular and biological characterization, taxonomic considerations, and potential for biological control. J. Virol. 83:12801-12812.

Choi, G., and Nuss, D. 1992. Hypovirulence of chestnut blight fungus conferred by an infectious viral cDNA. Science 257:800-803.

Cox-Foster, D. L., Conlan, S., Holmes, E. C., Palacios, G., Evans, J. D., Moran, N. A., Quan, P. L., Briese, T., Hornig, M., Geiser, D. M., Martinson, V., van Engelsdorp, D., Kalkstein, A. L., Drysdale, A., Hui, J., Zhai, J. H., Cui, L. W., Hutchison, S. K., Simons, J. F., Egholm, M., Pettis, J.S., and Lipkin, W. I. 2007. A metagenomic survey of microbes in honey bee colony collapse disorder. Science 318:283-287.

Fauquet, C. M., Mayo, M. A., Maniloff, J., Desselberger, U., and Ball, L. A., eds. 2005. Virus Taxonomy, Eighth Report of the International Committee on Taxonomy of Viruses. Elsevier Academic Press, San Diego, CA, U.S.A.

Feng, H. C., Shuda, M., Chang, Y., and Moore, P. S. 2008. Clonal integration of a polyomavirus in human Merkel cell carcinoma. Science 319:1096-1100.

Ghabrial, S. A. 1998. Origin, adaptation and evolutionary pathways of fungal viruses. Virus Genes 16:119-131.

Ghabrial, S. A., and Suzuki, N. 2009. Viruses of plant pathogenic fungi. Annu. Rev. Phytopathol. 47:353-384.

Giovannetti, M., and Mosse, B. 1980. An evaluation of techniques for measuring vesicular-arbuscular mycorrhizal infection in roots. New Phytol. 84:489-500.
Hagiwara, K., Higashi, T., Namba, K., Uehara-Ichiki, T., and Omura, T. 2003. Assembly of single-shelled cores and double-shelled virus-like particles after baculovirus expression of major structural proteins P3, P7 and P8 of Rice dwarf virus. J. Gen. Virol. 84:981-984.

Hijikata, N., Murase, M., Tani, C., Ohtomo, R., Osaki, M., and Ezawa, T. 2010. Polyphosphate has a central role in the rapid and massive accumulation of phosphorus in extraradical mycelium of an arbuscular mycorrhizal fungus. New Phytol. 186:285-289.

Hillman, B. I., Supyani, S., Kondo, H., and Suzuki, N. 2004. A reovirus of the fungus Cryphonectria parasitica that is infectious as particles and related to the Coltivirus genus of animal pathogens. J. Virol. 78:892898.

Kayama, M. 2001. Comparison of the aluminum tolerance of Miscanthus sinensis Anderss. and Miscanthus sacchariflorus Bentham in hydroculture. Int. J. Plant Sci. 162:1025-1031.

Koch, A. M., Kuhn, G., Fontanillas, P., Fumagalli, L., Goudet, J., and Sanders, I. R. 2004. High genetic variability and low local diversity in a population of arbuscular mycorrhizal fungi. Proc. Natl. Acad. Sci. U.S.A. 101:2369-2374.

Koonin, E. V., Wolf, Y. I., Nagasaki, K., and Dolja, V. V. 2008. The Big Bang of picorna-like virus evolution antedates the radiation of eukaryotic supergroups. Nat. Rev. Microbiol. 6:925-939.

Lumini, E., Bianciotto, V., Jargeat, P., Novero, M., Salvioli, A., Faccio, A., Bécard, G., and Bonfante, P. 2007. Presymbiotic growth and sporal morphology are affected in the arbuscular mycorrhizal fungus $G i$ gaspora margarita cured of its endobacteria. Cell. Microbiol. 9:17161729.

Maki, T., Nomachi, M., Yoshida, S., and Ezawa, T. 2008. Plant symbiotic microorganisms in acid sulfate soil: Significance in the growth of pioneer plants. Plant Soil 310:55-65.

Maldonado-Mendoza, I. E., Dewbre, G. R., and Harrison, M. J. 2001. A phosphate transporter gene from the extra-radical mycelium of an arbuscular mycorrhizal fungus Glomus intraradices is regulated in response to phosphate in the environment. Mol. Plant-Microbe Interact. 14:1140-1148.

Márquez, L. M., Redman, R. S., Rodriguez, R. J., and Roossinck, M. J. 2007. A virus in a fungus in a plant: Three-way symbiosis required for thermal tolerance. Science 315:513-515.

Nakamura, S., Yang, C. S., Sakon, N., Ueda, M., Tougan, T., Yamashita, A., Goto, N., Takahashi, K., Yasunaga, T., Ikuta, K., Mizutani, T., Okamoto, Y., Tagami, M., Morita, R., Maeda, N., Kawai, J., Hayashizaki, Y., Nagai, Y., Horii, T., Iida, T., and Nakaya, T. 2009. Direct metagenomic detection of viral pathogens in nasal and fecal specimens using an unbiased high-throughput sequencing approach. PLoS One 4:e4219. Published online.

Nielsen, J. S., Joner, E. J., Declerck, S., Olsson, S., and Jakobsen, I. 2002. Phospho-imaging as a tool for visualization and noninvasive measurement of $\mathrm{P}$ transport dynamics in arbuscular mycorrhizas. New Phytol. 154:809-819.

Osaki, H., Wei, C., Arakawa, M., Iwanami, T., Nomura, K., Matsumoto, N., and Ohtsu, Y. 2002. Nucleotide sequences of double-stranded RNA segments from a hypovirulent strain of the white root rot fungus Rosellinia necatrix: Possibility of the first member of the Reoviridae from fungus. Virus Genes 25:101-107.

Redecker, D., Kodner, R., and Graham, L.E. 2000a. Glomalean fungi from the Ordovician. Science 289:1920-1921.

Redecker, D., Morton, J. B., and Bruns, T. D. 2000b. Ancestral lineages of arbuscular mycorrhizal fungi (Glomales). Mol. Phylogenet. Evol. 14:276-284.

Salvioli, A., Chiapello, M., Fontaine, J., Hadj-Sahraoui, A. L., GrandmouginFerjani, A., Lanfranco, L., and Bonfante, P. 2010. Endobacteria affect the metabolic profile of their host Gigaspora margarita, an arbuscular mycorrhizal fungus. Environ. Microbiol. 12:2083-2095.

Sasaki, A., Kanematsu, S., Onoue, M., Oyama, Y., and Yoshida, K. 2006. Infection of Rosellinia necatrix with purified viral particles of a member of Partitiviridae (RnPV1-W8). Arch. Virol. 151:697-707.

Simon, L., Bousquet, J., Levesque, R. C., and Lalonde, M. 1993. Origin and diversification of endomycorrhizal fungi and coincidence with vascular land plants. Nature 363:67-69.

Smith, S. E., and Read, D. J. 2008. Mycorrhizal Symbiosis. Academic Press, London.

Spatz, S. J., and Rue, C. A. 2008. Sequence determination of a mildly virulent strain (CU-2) of Gallid herpesvirus type 2 using 454 pyrosequencing. Virus Genes 36:479-489.

Stielow, B., and Menzel, W. 2010. Complete nucleotide sequence of TaV1, a novel totivirus isolated from a black truffle ascocarp (Tuber aestivum Vittad.). Arch. Virol. 155:2075-2078.

Stielow, B., Klenk, H.-P., and Menzel, W. 2011a. Complete genome sequence of the first endornavirus from the ascocarp of the ectomycorrhizal fungus Tuber aestivum Vittad. Arch. Virol. 156:343-345. 
Stielow, B., Klenk, H.-P., Winter, S., and Menzel, W. 2011b. A novel Tuber aestivum (Vittad.) mitovirus. Arch. Virol. 156:1107-1110.

Suzuki, N., Maruyama, K., Moriyama, M., and Nuss, D.L. 2003. Hypovirus papain-like protease p29 functions in trans to enhance viral double-stranded RNA accumulation and vertical transmission. J. Virol. 77:11697-11707.

Tani, C., Ohtomo, R., Osaki, M., Kuga, Y., and Ezawa, T. 2009. Polyphosphate-synthesizing activity in extraradical hyphae of an arbuscular mycorrhizal fungus: ATP-dependent but proton gradient-independent synthesis. Appl. Environ. Microbiol. 75:7044-7050.

Thompson, J. D., Gibson, T. J., Plewniak, F., Jeanmougin, F., and Higgins, D. G. 1997. The CLUSTAL_X Windows interface: Flexible strategies for multiple sequence alignment aided by quality analysis tools. $\mathrm{Nu}-$ cleic Acids Res. 25:4876-4882.

Ueda, S., Masuta, C., and Uyeda, I. 1997. Hypothesis on particle structure and assembly of rice dwarf phytoreovirus: Interactions among multiple structural proteins. J. Gen. Virol. 78:3135-3140.

van Diepeningen, A. D., Debets, A. J. M., and Hoekstra, R. F. 2006. Dynamics of dsRNA mycoviruses in black Aspergillus populations. Fungal Genet. Biol. 43:446-452.

Wickner, R. B. 2001. In: Fields Virology. Lippincott Williams \& Wilkins, Philadelphia.

\section{AUTHOR-RECOMMENDED INTERNET RESOURCES}

National Bioresource Project Legume Base database: www.legumebase.agr.miyazaki-u.ac.jp

The National Center for Biotechnology Information database: www.ncbi.nlm.nih.gov

Wellcome Trust Sanger Institute Pfam database: pfam.sanger.ac.uk TreeView database: taxonomy.zoology.gla.ac.uk/rod/treeview.html 